\title{
A Ética da Informação em Simetria Ontológica: Notas para uma Aproximação Metodológica
}

\author{
The Information Ethics in Ontological Symmetry: Notes for a Methodological \\ Approach
}

\section{La Ética de la Información en Simetría Ontológica: Notas para un Enfoque Metodológico}

Jackson da Silva Medeiros ${ }^{1}$

\begin{abstract}
Resumo
Este trabalho tem como objetivo pensar a Teoria Ator-Rede como uma proposta metodológica, com vistas à integração dos estudos relacionados à ética da informação. Entende que os dispositivos eletrônicos, que auxiliam na produção e disseminação de informação, criam novos problemas e esses devem ser tratados de novas formas, uma vez que, havendo mudança no processo, há alteração na forma de análise e, em muitos casos, nos resultados obtidos. Como os dispositivos eletrônicos são potencialmente máquinas de ligações entre entidades de qualquer natureza, não há como relegar o potencial informacional proporcionado por esses aparatos, por isso uma análise ética da informação necessita de mecanismos metodológicos, como a Teoria Ator-Rede, capazes de apreender entidades com existência, independentemente de ser uma entidade com vida ou inanimada.
\end{abstract}

\begin{tabular}{|c|c|}
\hline & Acesse este artigo online \\
\hline \multirow{2}{*}{ 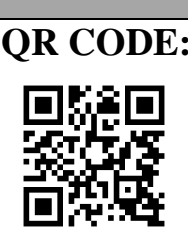 } & $\begin{array}{l}\text { Website: } \\
\text { http://www.revistas.ufg.br/index.php/ci }\end{array}$ \\
\hline & $\begin{array}{l}\text { DOI: } \\
\text { http://dx.doi.org/10.5216/ci.v20i1.45186 }\end{array}$ \\
\hline
\end{tabular}

Palavras-chave: Ética da Informação. Teoria Ator-Rede. Metodologia. Simetria. Ontologia.

\begin{abstract}
This paper aims to think the Actor-Network Theory as a methodological proposal aimed at integration of studies related to the information ethics. Understands that the electronic devices that assist the production and dissemination of information create new problems and these should be addressed in new ways, since there is change in the process there is change in the form of analysis and, in many cases, in the results. As electronic devices are potentially links between entities of any nature, there is no way relegating the informational potential offered by these devices, so an ethical analysis of the information needs methodological mechanisms, such as Actor-Network Theory, able to grasp entities with existence, whether an entity alive or inanimate.
\end{abstract}

Keywords: Information Ethics. Actor-Network Theory. Methodology. Simmetry. Ontology.

\footnotetext{
1 Doutor em Comunicação e Informação pela Universidade Federal do Rio Grande do Sul. Professor do Departamento de Ciências da Informação da mesma Universidade. Brasil, Rio Grande do Sul, Porto Alegre. Email: jackson.medeiros@ufrgs.br
}

Comun. \& Inf., Goiânia, GO, v. 20, n. 1, p. 4-25, jan./jun. 2017 


\section{Resumen}

Este trabajo tiene como objetivo pensar en TeoriaAtor-Rede como una propuesta metodológica con vistas a la integración de los estudios relacionados con la ética de la información. Entiende que los dispositivos electrónicos que se prestan en la producción y la difusión de la información crean nuevos problemas y se tratan de nuevas formas, una vez que hay un cambio no proceso en la forma de análisis, en muchos casos, en los resultados. Como los dispositivos electrónicos son potencialmente máquinas de ligación entre entidades de la naturaleza, no hay como relegar el potencial informativo de estos dispositivos, por eso una evaluación de la información necesaria de los mecanismos metodológicos, como un Teoria Ator-Rede, con independencia de ser una entidad con vida o inanimada.

Palabras clave: Ética de la Información. Teoría Actor-Red. Metodología. Simetría. Ontología.

\section{INTRODUÇÃO}

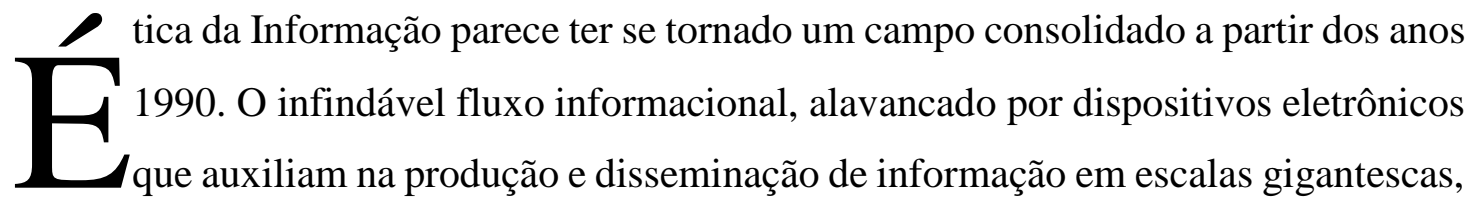
faz com que novos problemas sejam sempre tratados de novas maneiras, uma vez que, havendo mudança nesse processo, há modificação na forma de análise e, em muitos casos, nos resultados obtidos.

Já passou a época em que computadores eram vistos apenas como calculadoras capazes de lidar com grande quantidade de dados. Nesse sentido, atualmente lança-se luz, principalmente, à informação em formato digital, impulsionada a partir da utilização em massa de dispositivos eletrônicos conectados à internet, os quais fazem com que a informação seja ainda mais pervasiva, merecendo destaque na forma como é analisada.

O que preocupa e se torna uma questão digna de pesquisa quando tratamos de Ética da Informação, nasce na própria natureza do conceito de informação. Isso envolve a sua complexidade de conceituação bem como seu fluxo. Indo nessa direção, a informação, enquanto informação per se, já seria essencialmente um objeto propício para o estudo da ética, mas pode ser vista também a partir de seus desdobramentos e de seu impacto na sociedade, acompanhada, em geral, do uso de tecnologias para sua comunicação e como isso altera a relação homemhomem, homem-máquina e (por que, não?) máquina-máquina.

Advogamos, e isto nos parece claro, que os dispositivos eletrônicos são potencialmente máquinas de ligações entre entidades de qualquer natureza, capazes de modificar aspectos sociais, econômicos, políticos, culturais etc. Não há como relegar o potencial informativo proporcionado por esses dispositivos, por isso uma análise ética da informação cresce em

Comun. \& Inf., Goiânia, GO, v. 20, n. 1, p. 4-25, jan./jun. 2017 


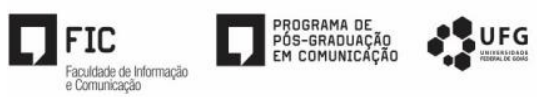

importância quando lidamos com situações que interferem em um processo crucial do ser humano: $\mathrm{o}$ ato de conhecer.

Johnson (2004) corrobora com isso ao dizer que os itinerários tramados pela utilização de computadores e suas formas de interação permitem a realização de atividades rotineiras, como viajar, trabalhar e entreter-se a partir de novos caminhos e de novos recursos, isto é, a partir de novas modalidades que a vida antes da existência dos dispositivos digitais não permitia. Isso é dado, podemos conceber, pelas novas formas de lidar com a informação, carregada de significados e com potencial de alterar os nossos estoques mentais de conhecimento e de formas do que chamamos de social, fazendo com que atuemos de modo constante e modificador no mundo a partir desses aparatos.

Isso significa dizer que a escolha de uma metodologia para esse tipo de estudo/análise deve ser resposta a um posicionamento ético na relação da informação com seu produtor e com seu receptor, primando ser capaz de sustentar um sistema de significados e de valores, baseados na construção cultural de uma sociedade. Isso está ligado à compreensão de que uma visão antropocêntrica não apenas nubla a significação da metodologia, mas também é contrária ao seu intuito.

Nossa proposta, baseada em um olhar qualitativo, nasce no alerta de Mansano (2012, p. 3) sobre a utilização desse tipo de método para o desenrolar de uma pesquisa, uma vez que a pretensão é "acompanhar o movimento como um método em movimento, atento à composição provisória dos dados e investigando sua funcionalidade naquela circunstância específica”. É esse suporte de análise que pretendemos explorar, uma vez que, ainda segundo a autora, esse tipo de pesquisa permite que a heterogeneidade de elementos dispostos e percorridos se mostre distante de categorias estabilizantes, mantendo sempre o quadro de uma representação momentânea da complexidade em campo.

Dessa forma, valemo-nos de Johnson (2004) quando percebe que o campo da ética computacional (o qual estendemos para a Ética da Informação) preocupa-se em constantemente verificar e compreender seu domínio, suas metodologias e sua essência, bem como a relação com outras disciplinas. Isso se torna essencial, pois, do modo como a tecnologia evolui e a produção de informação aumenta, novas questões são suscitadas e, consequentemente, novas respostas terão de ser buscadas, fazendo com que as teorias e metodologias já consolidadas e aplicadas ao campo da Ética nem sempre tragam resultado esperados. 
O que pretendemos trazer são elementos que resultam de uma apreensão, sempre parcial, de uma heterogeneidade baseada no contexto. Buscamos o que Mansano (2012, p. 2) aponta ser um tipo de distanciamento "das generalizações e das verdades instituídas, [sendo que] a problematização está mais preocupada com a criação, multiplicação e variação das perguntas do que propriamente com a fixação em respostas categóricas". Nesse sentido, buscamos elementos da Teoria Ator-Rede (ANT) - compreendida, acima de tudo, como um método - para compor um olhar calcado no princípio da simetria entre as entidades e, por conseguinte, na sua atuação como uma presunção ética para o desenvolvimento de estudos de informação.

Objetivamos, em linhas gerais, buscar elementos, características e/ou princípios na ANT que permitam balizar estudos ligados à Ética da Informação, particularmente no que está relacionado ao princípio de igualdade das coisas. Nesse sentido, e com consciência de que esta é uma proposta em estruturação, o trabalho está baseado em uma metodologia qualitativa de análise de materiais bibliográficos que promovem discussão sobre os temas Ética da Informação, como em Capurro (2006; 2014), Floridi (1999; 2010), Froelich (2004), Johnson (2004) eMoor (1985) e Teoria Ator-Rede, a partir de Latour (2000; 2009; 2012), Law (1992) e Lemos (2010). Durante o desenrolar da discussão, ao tecer algumas considerações finais, pontuamos elementos que julgamos pertinentes à proposição da Teoria Ator-Rede como instrumento metodológico com características de respeito aos elementos de um estudo ligado à Ética da Informação.

\section{INFORMAÇÃO NA ÉTICA DA INFORMAÇÃO}

A informação é um elemento capaz de alterar estruturas ${ }^{2}$, fazendo com que o receptor, ao decodificar os elementos da mensagem, possa atribuir significado a ela. É, então, insumo para a produção de conhecimento (ação a partir de significado), uma criação de novidade, da capacidade de pavimentar gaps de conhecimento. Isso faz com que as estruturas prévias possam ser alteradas, conduzindo um indivíduo a um melhor estado em relação a si próprio e à sociedade como um todo (BARRETO, 1994).

Se o homem é capaz de lidar com uma estruturação simbólica a partir da representação que faz do mundo, esta não é direta, mas é dada por um tipo de mediação, a qual passa pela

2 Entendemos que, ao mesmo tempo em que altera estruturas, a própria estrutura da informação está em transformação. Dado o espaço e o escopo deste trabalho, essa noção será desenvolvida em outro estudo.

Comun. \& Inf., Goiânia, GO, v. 20, n. 1, p. 4-25, jan./jun. 2017 
cultura e seu poder de preservar, transmitir e ordenar o conhecimento, provendo sentido às relações. Isso significa dizer que a informação por si só não altera o ser humano ou a sociedade, mas fornece subsídios para que isso seja feito (ARAÚJO, 2001).

Concordando que o sentido do mundo é dado pela informação, Luciano Floridi (2010) faz uma separação das circunstâncias que envolvem a informação nesse âmbito. Para o autor, a informação pode ser vista a partir de três ângulos: informação como recurso; informação como produto; informação como objetivo.

O primeiro caso - informação como recurso - diz respeito à posse da informação por um indivíduo com vistas às ações que ele fará a partir da reunião desse insumo. Ou seja, possuir a melhor informação possível pode ser decisivo para a melhor tomada de decisão praticável. Nessa perspectiva, anota Floridi (2010, p. 105), “[...] parece que a máquina moral precisa de informação, e muita, para funcionar corretamente". O segundo elemento - informação como produto - está ligado à elaboração e compartilhamento da informação gerada a partir do recurso utilizado. Isto é, além da íntima ligação com a informação como recurso, atua na produção, tendo suas ações no registro, na disseminação e no comprometimentoem ser ativo da confiança naquilo que foi produzido. Já a informação como objetivo - terceiro elemento - atua nas ações que afetam o ambiente informacional, como a privacidade, por exemplo. Nessa esfera está a questão de acesso não autorizado a determinado sistema ou informação, sendo que a questão não é que ações foram tomadas com aquelas informações acessadas, mas a relevância e o que significa o acesso não autorizado. Ou seja, é a ação realizada a partir do reconhecimento da informação e do seu uso (FLORIDI, 2010).

Isso serve como base para uma conceituação da Ética da Informação, já que permite compreensão sobre “[...] a problematização de regras de comportamento sobre o que é permitido ou não a ser comunicado, por quem e em que meio devido a mudanças básicas e desafios nas estruturas de poder de comunicação em uma dada sociedade" (CAPURRO, 2006, p. 176). Em linhas gerais, a Ética da Informação está ligada ao estudo do empreendimento conceitual e moral com atenção voltada à criação, à organização, à disseminação, ao uso, à privacidade, à propriedade intelectual do fenômeno informação, entre outros elementos, isto é, ao fluxo informacional como um todo.

Em uma conceituação mais densa, Capurro (2014, p. 9-10) propõe que a Ética da Informação está ligada ao

espaço de reflexão cujos objetos são as regras e valores vigentes implícita ou explicitamente nesse meio de interação digital, podendo se entender também

Comun. \& Inf., Goiânia, GO, v. 20, n. 1, p. 4-25, jan./jun. 2017 
que tal termo inclui meios de comunicação não digitais, como tem sido, e segue sendo a comunicação oral e escrita e, particularmente, a comunicação impressa. Tanto a definição do referido ao bem comum ou à propriedade privada no que se refere à livre expressão das pessoas e respeito por aquilo que eles não querem que seja comunicado além de um núcleo de pessoas, incluindo a possibilidade de intimidade pessoal, ou seja, todo campo do que diz respeito à diferença entre o público e o privado deve ser objeto de uma reflexão crítica em que você joga, nem mais, nem menos, do que a concepção de liberdade individual e coletiva. [...] Essa reflexão tem como horizonte, por um lado, um mundo compartilhado, assim como princípios e valores que foram decantados através dos séculos como regras básicas universais ou universalizáveis de uma vida humana que mereça esse nome. Mas essas regras e valores não são exercidos, por outro lado, em um espaço abstrato, herdeiro das ideias platônicas ou dos princípios absolutos proclamados pelas religiões e seus substitutos seculares, mas em histórias e linguagens contingentes, nas quais se expressam diversas formas de autocompreensão de si mesmo e do mundo, bem como são baseados em interesses de poder, regras vigentes de verdade e credibilidade e opções frente às possibilidades cujas consequências são, ao menos, imprevisíveis e, em alguns casos, irreversíveis (CAPURRO, 2014, p. 9-10).

Essa ampla acepção requer aporte interdisciplinar que possibilite a construção de um arcabouço que será sempre modificado e ampliado, uma vez que a perspectiva ética vai sendo moldada a partir do avanço das sociedades e deseus escopos de análise e de atuação, que se ampliam, cada vez mais, a partir da complexidade com que o mundo molda seus indivíduos e vice-versa. Assim, a complexidade é, como Morin (2011) descreve, uma via de mão dupla, na qual o sujeito é autônomo e dependente, ao mesmo tempo, sendo ligado a uma espécie de desordem que permeia os diversos parâmetros e paradigmas, permitindo que uma reunião de elementos cubra hiatos advindos de novas descobertas, de novas reflexões.

Isso é próximo do que Froelich (2004) relata sobre a junção de disciplinas/áreas que estudam Ética da Informação: isso pode ser visto com uma confluência de preocupações éticas de mídia, jornalismo, biblioteconomia e ciência da informação, ética computacional (incluindo ciberética), sistemas e gestão da informação, negócios e da internet. A própria literatura relata a variedade de tópicos e disciplinas que atuam e são atravessadas pela área de Ética da Informação, oferecendo grande escopo de estudos, uma vez que cada campo e seus estudiosos têm suas necessidades, parâmetros, métodos e/ou interesses, mas alertando que os problemas não são mais de uma área específica, mas, sim, de todas as áreas que se preocupam com a informação.

Utilizamos a opinião de Capurro (2014) para dizer que as questões que envolvem a Ética da Informação estão ligadas às dimensões culturais (interculturais, na ideia defendida pelo

Comun. \& Inf., Goiânia, GO, v. 20, n. 1, p. 4-25, jan./jun. 2017 
autor) que abrangem aspectos amplamente tratados pela cultura, não pretendendo determiná-la. Compreende reflexões que vão desde a análise da moral aplicada a um objeto (informação, nesse caso) até questões que envolvam, por exemplo, privacidade ou a utilização de algoritmos para coleta e análise de dados - algo relativamente comum nos dias de hoje com tanta informação online disponível sobre os indivíduos conectados na rede.

Estamos diante de uma análise que envolve comportamento a partir de um ponto de vista, em uma posição que nunca é neutra. Isso é culturalmente colocado quando ligado a tempos e a espaços, fazendo com que seja possível a explicação de questões morais de forma sistemática, buscando ou não universais recomendáveis ou que possam refletir o "desejo ideal" como padrão de comportamento ${ }^{3}$.

Interessante é perceber, acompanhando o pensamento de Johnson (2004), novos caminhos delineados a partir do estudo da Ética na sua relação com a informação, uma vez que surgem com o tipo de tecnologia utilizada, de acordo com o setor onde ocorre a utilização e com os conceitos e princípios éticos não estabilizados em virtude de características próprias do meio. Todo esse escopo, ainda segundo a autora, ocorre em um bojo de incertezas morais.

Tomando esse prisma, a abrangência da Ética da Informação está ligada aos aspectos morais e legais que a informação agencia. Ou seja, levando em consideração a complexidade do lidar com informação, o campo perpassa e congrega diversas áreas de estudo e de aplicação, atuando, de modo geral, mas não apenas, a partir da aplicação das tecnologias da comunicação e da informação na sociedade, construindo um sistema reflexivo e crítico do que é tratado. Isso ocorre, como Moor (1985) observa, porque há, em geral, um vácuo de políticas sobre a utilização de dispositivos eletrônicos de comunicação da informação, fazendo com que os problemas gerados necessitem de constante vigilância conceitual.

[...] há um vácuo de políticas sobre como a tecnologia computacional deve ser usada. Computadores nos fornecem novas capacidades e esses, por sua vez, dão-nos novas escolhas para a ação. Frequentemente não existem políticas de conduta nessas situações ou políticas existentes parecem inadequadas. A tarefa central da ética de computador é determinar o que devemos fazer em tais casos, como, por exemplo, formular políticas para guiar nossas ações. Claro, algumas situações éticas nos confrontam como indivíduos e como sociedade (MOOR, 1985, p. 266).

3 O estabelecimento de padrões universais é um tema complexo na Ética e, por consequência, na Ética da Informação. Com vertentes a favor e contra essa ideia, outros estudos precisam ser conduzidos para que se possa discutir essa ideia.

Comun. \& Inf., Goiânia, GO, v. 20, n. 1, p. 4-25, jan./jun. 2017 
As palavras de Moor atestam o que a Ética tradicional aponta como seu escopo de atuação, corroborando o que entendemos como a existência de uma tênue linha entre o que se deve fazer, o que se pode fazer e o que se quer fazer. Isso está entre a legalidade, regida por leis e sanções impostas por entidades superiores e controladoras dos indivíduos, e a possibilidade de o próprio ser humano impor suas vontades.

Dito dessa maneira, há a improbabilidade de aplicação de teorias éticas já estabelecidas por longa tradição dentro da Filosofia, uma vez que esse vácuo de políticas está intimamente ligado à existência de um vácuo conceitual, podendo, se aplicadas teorias já estabelecidas para um mundo diferenciado ${ }^{4}$, causar inconsistências de análises. A Ética da Informação está, então, preocupada nesse desenvolvimento de uma estrutura conceitual que possa dar conta dos aspectos computacionais e informacionais na sociedade baseada nesses elementos. Nas palavras de Johnson (2004, p. 66): "Não temos regras, políticas e convenções de como comportar-nos em relação às novas possibilidades".

As questões éticas surgem em contextos do mundo real e problemas da ética computacional surgem nos contextos em que os computadores são usados. Cada contexto ou setor tem problemas distintos, e se ignorarmos este contexto, podemos perder aspectos importantes [...] (JOHNSON, 2004, p. 66).

Entendendo que a Ética da Informação está ligada ao reconhecimento e à análise da ligação entre as tecnologias da comunicação e seus objetos informacionais com as ações humanas, com vistas a uma fundamentação filosófica e social, bem como possibilitar a conexão das ações humanas ao estudo ético, podemos dizer, com certa margem de segurança, que as ações humanas são alteradas pela inserção das tecnologias da comunicação e da informação em ambiente cotidiano. Essa assimilação nem sempre é clara ou percebida, mas é essencial para o acontecimento de nossas vidas em um mundo conectado.

Mesmo uma pessoa que não se utiliza particularmente de dispositivos digitais necessita deles. Ir a um banco sacar dinheiro em um caixa eletrônico ou mesmo em um guichê faz com que algum tipo de tecnologia da informação e da comunicação seja ativada, afinal, o bancário, ao realizar o atendimento, utiliza-se de um sistema informático que solicita e fornece dados para que se possa efetivar a ação solicitada. O mesmo serve para um supermercado, para uma compra feita com cartão de crédito ou de débito, serve também para os serviços de uma

\footnotetext{
4 Dizemos diferenciado porque os estudos ligados à ética tradicional não contemplam, por exemplo, as questões ligadas à internet ou às redes sociais que se criam em ambientes virtuais e que apresentam características diferentes do mundo físico.
} 
biblioteca, onde o atendente ativa uma série de serviços ligados em rede para poder realizar o empréstimo ou a devolução de uma obra.

É relevante que ao estudarmos esses processos possamos perceber e incluir os objetos não humanos. Para isso é primordial encontrar e utilizar metodologias que não coloquem apenas o ser humano como centro de um processo em que, na realidade, o homem é mais um ator em uma rede de entidades heterogêneas. Essa é a proposta da Teoria Ator-Rede, a qual trataremos a seguir.

\section{TEORIA ATOR-REDE (ANT)}

Uma noção de rede pode ser vista sob o olhar em relação à sociedade, podendo ser compreendida como fios que se ligam uns aos outros. Sua análise é possível a partir de quando se percebe o modo como esses fios se ligam de forma recíproca, sem descuidar das tensões e/ou estrutura interna da própria rede que altera a forma como a individualidade ocorre (ELIAS, 1994).

A rede não é algo rígido, sendo que a ordem a ser estabelecida nasce de diversas unidades, não podendo ser vista de maneira individualizada pois está “em constante movimento, como um tecer e destecer ininterrupto das ligações" (ELIAS, 1994, p. 35), trazendo uma noção de possível flexibilização do que se pretende analisar. Como anota Latour (2009, p. 9): "mais flexível que a noção de sistema, mais histórica que a de estrutura, mais empírica que a de complexidade, a rede é o fio de Ariadne dessas histórias confusas".

Seguindo nesse percurso, compreendemos, à luz de Latour, que a ideia de rede proposta pela Teoria Ator-Rede (ANT) é uma nova forma de encarar a problemática da "produção social do conhecimento científico", porque "se conecta ao mesmo tempo à natureza das coisas e ao contexto social, sem, contudo, reduzir-se nem a uma coisa nem a outra" (LATOUR, 2009, p. 11).

Assim, uma rede é, como aponta Moraes (2004), uma lógica de conexões definidas por seus agenciamentos internos e não por seus limitadores externos, não existindo pontos que mereçam ser privilegiados, caracterizando uma totalidade aberta e capaz de se relacionar e crescer em todas as direções. Para traçar redes, a ANT abre mão de uma suposta linha divisória entre humanos e não humanos, percebendo as entidades como uma grande rede conectada que se modifica constantemente a partir das relações que se estabelecem em diversos níveis. 
A ANT busca desconstruir a percepção de mundo tradicionalmente enraizada em valores políticos e epistemológicos. Os estudos propostos pela ANT tentam, segundo Latour, reconstruir o que foi perdido na Sociologia ao longo do tempo, ou seja, o poder de realizar e perceber associações, opondo-se aos estudos ditos sociais, os quais buscam a existência de um contexto social que influencia, que atua e que estabelece características explicativas por sua categorização.

Esse contexto social é o que muitos pesquisadores utilizam como "uma esfera específica da realidade; pode ser usado como um tipo especial de causalidade para explicar os aspectos residuais que escapam a outros domínios" (LATOUR, 2012, p. 20-21). Isso significa dizer que as explicações aceitas pela ANT não dizem respeito a existência de "mãos invisíveis" supostamente capazes de controlar/categorizar/explicar determinada situação.

O argumento central de Latour (2012, p. 51-52) em favor da ANT é que "não há grupo relevante ao qual possa ser atribuído o poder de compor agregados sociais, e não há componente estabelecido a ser utilizado como ponto de partida incontroverso". Isto é, não há um processo de relacionamento concebido de antemão, uma vez que os laços são frágeis e podem apresentar mudanças sem prévio aviso.

A não adoção de uma postura delimitadora faz com que os analistas devam seguir seus atores, sem distinção de natureza, tanto na formação quanto no desmanchar de grupos. Isso se dá porque o que se pretende estabelecer é que "todos os elementos heterogêneos precisam ser reunidos de novo em uma dada circunstância" (LATOUR, 2012, p. 23), uma vez que não se pode entender as associações como sendo regidas pelo social, mas o social como resultado de associações.

[...] a incômoda resposta que se obtém em relação aos famosos 'contextos' é que existe alguma coisa que possibilita a interação, ao trazer para a cena a maioria dos seus ingredientes necessários, mas que essa 'alguma coisa' ao mesmo tempo está presente por trás e é demasiado abstrata para fazer o que quer que seja. A estrutura é muito poderosa, e no entanto demasiado fraca e remota para ter qualquer eficácia. [...] as próprias estruturas permanecem demasiado abstratas porque não foram convocadas, mobilizadas, realizadas ou encaradas em algum tipo de interação local e vivida (LATOUR, 2012, p. 243245).

A estrutura não é um corpo acima de nossas cabeças que dispõe de categorias as quais nos encaixamos. A estrutura é fornecedora de elementos e é, ao mesmo tempo, alimentada, por isso a forma de rede é preciosa. Colocando de forma mais clara: "a ANT é antes de tudo um princípio de projeção abstrato para desenhar qualquer forma, não uma decisão arbitrária sobre

Comun. \& Inf., Goiânia, GO, v. 20, n. 1, p. 4-25, jan./jun. 2017 
qual forma deva estar no mapa" (LATOUR, 2012, p. 257). Estudar como certo ente é mais poderoso ou maior não deve ser o foco da ANT. A perspectiva é que se estabeleça como tamanho, poder e organização são gerados (LAW, 1992).

Acompanhando isso, Latour (2012) chega a afirmar que nem a sociedade nem o social existem na forma de uma estrutura. A forte afirmação está baseada nas mudanças das ligações entre os atores, ou seja, a sociedade, ou o social, é uma produção constantemente construída, sendo a ANT uma ferramenta que permite analisar esse processo. "A sociedade é a consequência, não a causa das associações. [...] não é o social que explica as associações, mas as associações que explicam o social" (LATOUR, 2012, p. 340).

Latour (2012) toma cuidado ao esclarecer que a ANT não atua apenas como um conjunto de entidades já reunidas, como uma sociedade, mas como um ajuntamento de novas entidades que ainda não estão reunidas, podendo ser chamadas de coletivo. Um coletivo repleto de conexões entre humanos e objetos, humanos e humanos e objetos e objetos, que não estabelece relação, a priori, entre o mundo material e o mundo social.

Não havendo separação prévia entre o mundo dos seres vivos e dos seres inanimados, os elementos se reúnem e se engendram de forma a não levar em conta princípios essencialistas de separação. Compreender essa configuração permite ir adiante, apoiados em uma perspectiva que não aceita categorizações prévias (MORAES, 2004; FREIRE, 2006).

O social que constitui a sociedade representa apenas uma parte dos grupos formadores do coletivo. Para reagrupar o social, será necessário, afora a circulação e a formatação de laços sociais tradicionalmente concebidos, descobrir outras entidades que circulem (LATOUR, 2012, p. 333).

Sabendo que a conjuntura básica é permitir e observar a existência de uma simetria entre humanos e não humanos, isso "significa não impor a priori uma assimetria espúria entre ação humana intencional e mundo material de relações causais" (LATOUR, 2012, p. 114). Com isso, superamos essa divisão dualista em geral imposta pela categorização, pelo privilégio ou até mesmo "esquecimento" de elementos antes da entrada em um domínio, possibilitando que se analise os poderosos da mesma forma que quaisquer outras entidades (LAW, 1992).

Se é um grande equívoco metodológico restringir de antemão e no lugar do ator o alcance das entidades que devem povoar o mundo social, seria tanto ou mais patético não reconhecer o trabalho incansável que fazem para limitar o repertório dos actantes e manter as controvérsias a distância (LATOUR, 2012, p. 325). 
Enxergar os objetos como parte de uma rede é tratar sua existência como essencial para a constituição da mesma. Sua incorporação ocupa lugar nas discussões e relatos de pesquisas, não atuando apenas como uma peça que tem seu lugar relegado, mas como peça-chave em muitas concepções do que acontece em um ambiente. Realizar uma ação implica a utilização de outra(s) entidade(s); não é possível agir só. A ação é acompanhada por objetos de essências variadas que formam uma rede da ação executada.

Se esse coletivo é formado pela interação dos atores, a sua composição, como aponta Law (1992), é uma questão de preferências não somente entre os humanos, mas também entre os não humanos. O que se deve apreender é a complexidade que envolve o processo. Nesse passo não é mais importante privilegiar um humano a um não humano ou vice-versa. A investigação deve levar em conta a proliferação de $\operatorname{actantes}^{5}$ que sejam relevantes ao caso. Como mostra Lemos (2010, p. 16):

[...] atores humanos e não humanos agem em rede e constituem-se eles mesmos como rede. Não há claramente sujeito e objeto, nem causa ou efeito predeterminados. Cada nó de uma rede de ação, por exemplo, dirigir um carro, ver TV, usar um celular ou um laptop, convoca uma série de atores humanos e não humanos. As relações sociais, morais ou éticas que daí emergem não podem ser avaliadas a priori ou a partir de um elemento central causal. [...] Considerar as ações na vida social é considerar os diversos fatores como agentes e as ações como parte de uma rede de relações (LEMOS, 2010, p. 16).

A análise, então, transforma-se em um processo de incertezas, principalmente no que se refere ao conjunto de entidades do mundo. O não delimitar antecipado de entidades, sejam elas de qualquer natureza, faz com que movimentos em torno de fatores complexos sejam aflorados, um desdobramento que torna a coisa múltipla, seja em suas associações, seja em si própria a partir de observações que permitam esboçar uma rede que, ao ser formada por entidades complexas, adquire também o status de complexa.

$\mathrm{Na}$ rede, cada elemento é simultaneamente um ator, cuja atividade consiste em fazer alianças com novos elementos, e uma rede, capaz de redefinir e transformar seus componentes. Os agentes sociais, portanto, não estão 'contidos' unicamente em corpos: um ator é uma rede moldada por relações heterogêneas, ou seja, ele é um efeito de rede que, por sua vez, participa e

5 Os actantes são "agentes, humanos ou não, mobilizados para a composição de redes temporárias engajadas em programas de ação" (HOLANDA; LEMOS, 2013, p. 2). Um agente "habita um conjunto de elementos (incluindo obviamente o corpo) que se estende por uma rede de materiais, somáticos e de outros tipos, que circundam cada corpo" (LAW, 1992, p. 384). Neste sentido, o argumento da ANT passa pela extrapolação do ser humano como entidade que carrega diversas atividades - por exemplo pensar, escrever, amar etc. - , fazendo com que outros atores também existam fora do corpo (LAW, 1992). Ator-Rede: quando um ator também é uma rede.

Comun. \& Inf., Goiânia, GO, v. 20, n. 1, p. 4-25, jan./jun. 2017 
molda outras redes. Na medida em que a rede se caracteriza por estabelecer um campo de tensões heterogêneas, a síntese não é um resultado necessário. (PEDRO, 2008, p. 4).

A compreensão dos não humanos - máquinas, textos, dinheiro, conceitos etc. - em conjunto com os humanos cria uma coletividade em que as ausências ou a retirada deliberada desses entes de análises faz com que a essência da sociedade, em sua acepção coletiva, perca sentido. Como retirar de análise algum tipo de engenhoca que permite o funcionamento de um sistema mais complexo? Como retirar a mesa ou o computador da análise sobre a escritura de um artigo?

Por isso as redes são heterogêneas. Por não se utilizar aqui a concepção de sociedade como uma macroestrutura categorizante, essa heterogeneidade produz o que compreendemos por entidades e, ao mesmo tempo, redes sociotécnicas, onde o ator é fundamentalmente conhecido como ator-rede (actante), percebendo que "ao falarmos de ator, deveremos sempre acrescentar a vasta rede de vínculos que o levam a atuar" (LATOUR, 2012, p. 313). Quando chamamos a baila uma rede sociotécnica, na realidade, o que invocamos é uma dinâmica associativa entre actantes, sejam eles humanos ou não.

Nesse âmbito é reafirmada a importância de olhar todas entidades, não caracterizando objetos apenas como ferramental de um ator humano. Os objetos têm colocação no espaço e no tempo e são cruciais para a demanda de movimentos de uma rede.

Os objetos técnicos que permeiam nosso cotidiano não são aqui concebidos como meros instrumentos a serviço da sociedade ou como suporte de algo que lhes é externo. São agentes/actantes capazes de engendrar transformações que ultrapassam o âmbito técnico-instrumental, participando da configuração de processos que não mais podemos definir como estritamente sócio-culturais passamos a nos referir a eles, doravante, como sócio-técnicos (PEDRO, 2008, p. 3).

Embora não haja teoria que contemple o "descobrimento de atores", sabemos que o importante é considerar que o número de atores de uma rede deve ser aumentado, uma vez que os objetos também agem, pois a vinculação social "é antes o nome de um movimento, um deslocamento, uma transformação, uma translação, um registro. É uma associação entre entidades de modo algum reconhecíveis como sociais no sentido corriqueiro" (LATOUR, 2012, p. 99). Não há forma, apenas movimentos. Esses designam formas novas e diferenciadas. A multiplicidade de atores é composta também pelas "entidades que foram explicitamente banidas da existência coletiva por mais de um século de explicações sociais” (LATOUR, 2012, p. 105).

Comun. \& Inf., Goiânia, GO, v. 20, n. 1, p. 4-25, jan./jun. 2017 


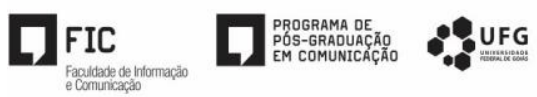

Isso deve ser explicado a partir de relatos que permitam a clareza necessária e não justificada por formas pré-concebidas, ou seja, não deve haver substituição de uma entidade por outra, de um fenômeno por outro. Devemos investigar as entidades e possibilitar que sejam explicadas não como "um feito cognitivo misterioso, mas um empreendimento de construção de mundo muito prático que consiste em ligar entidades a outras entidades, ou seja, em traçar uma rede" (LATOUR, 2012, p. 152).

A ANT é conduzida pelo que Latour (2012, p. 158) chama de tradução ou de translação. Mesmo não sabendo que posição cada ator possui no plano simétrico, é sabido que "podem estar associados de tal modo que eles fazem outros fazerem coisas", entendendo que são as transformações dos eventos que explicam o social. Quer dizer, “[...] a concatenação dos mediadores não traça as mesmas ligações e não requer o mesmo tipo de explicações como um séquito de intermediários transportando uma causa" (LATOUR, 2012, p. 158).

A tradução está baseada na "interpretação dada pelos construtores de fatos aos seus interesses e aos das pessoas que eles alistam" (LATOUR, 2000, p. 178), referindo-se à "hibridação, mestiçagem, multiplicidade de conexões mais do que à repetição de elementoschave. A tradução é sustentada por uma ontologia definida por sua hibridação" (MORAES, 2004, p. 326). Essa mistura subjetiva aportada pela tradução é que alimenta a origem do conhecimento, indo além da simples interação linear entre humanos.

Conceito importante é o de mediação (mediador): “[...] mediadores transformam, traduzem, distorcem e modificam o significado ou os elementos que supostamente veiculam" (LATOUR, 2012, p. 65). Essa diferença conceitual traz caráter complexo aos atores, fazendo com que os mediadores produzam caminhos que são uma produção contínua de sociedade.

A mediação atua como critério de operacionalização da ação de um actante, sendo este entendido como um mediador a partir de suas ações. Assim, a mediação funciona como "um elo que coloca os sujeitos em relação, humanos e não humanos. São eles que agenciam e produzem transformações nas redes sociotécnicas" (LEMOS, 2010, p. 17), nas quais "mediações geram redefinições da realidade, tecendo novas geografias e novos controles. Novas coerções exercem pressão sobre velhas coerções e as deslocam, descentram" (NOBRE; PEDRO, 2010, p. 48).

Com isso uma ação atua como uma ligação a partir dos diversos atores que desempenham seus papéis, sendo "assumida por outros" (LATOUR, 2012, p. 73). Isso serve 
como elemento diferenciado, já que a ação revela um caráter mediador, transformador, sendo o ator não apenas aquele que emana ações, mas também alvo delas, agindo e fazendo agir.

Isso leva a relatar incessantemente como uma ação se desenvolve, uma vez que os mediadores não têm os efeitos de um ato ligados obrigatoriamente a uma causa, mas sim à determinada circunstância que acarreta na ação. Uma vez que não há como atribuir determinada situação ao pré-estabelecimento contextual, "se você mencionar uma ação, terá de apresentar um relato sobre ela" (LATOUR, 2012, p. 84), fazendo com que "a presença do social tem de ser repetidamente demonstrada e não simplesmente postulada" (LATOUR, 2012, p. 85).

Isso possibilita notar que a rede não diz respeito a pontos sendo ligados ou que entidades com maior poder são centro da rede e a gerenciam. Há uma difusão do poder existente na rede, podendo estar distribuído e/ou explícito em alguns nós, fazendo com que a ordem não seja fixa, sendo visualizados movimentos que estipulam novos espaços (NOBRE; PEDRO, 2010).

Conhecer a estrutura que está posta a partir de um trabalho que agregue entidades heterogêneas é também um trabalho de superação de poderes, de resistências, um trabalho que, a partir da descrição do movimento da rede, das ações, é eticamente propositivo. A possibilidade de conhecer esses elementos e seus vínculos permite que consigamos revelar e ordenar sua coletividade em constante construção e desconstrução.

\section{NOTAS PARA UM PENSAR METODOLÓgICO SOBRE A ÉTICA DA INFORMAÇÃO A PARTIR DA TEORIA ATOR-REDE}

Pensar a ANT como uma metodologia adquire características de um raciocínio propositivamente ético, uma vez que busca congregar entidades que, em muitos casos, são preteridas, mas que, na verdade, atuam de forma decisiva na construção de redes de ações. Não há vida sem objetos e trazer a constante visão biocêntrica aos estudos (informacionais) é, como ressaltamos a partir de Law (1992), uma escolha de separação analítica, e, com certeza, não uma visão ética.

Floridi (2010, p. 109) aponta, nesse sentido, para aspectos que devem ser levados em consideração quando se estuda esses processos ético-informacionais: "Isso significa analisar informacionalmente todas as entidades envolvidas [...] e suas alterações, ações e interações, e tratá-las não como apartadas, mas como parte do ambiente informacional ao qual pertencem como próprios sistemas informacionais". Entendemos que isso se caracteriza como um 
pensamento ético e estabelece a relação recíproca entre a Teoria Ator-Rede e a Ética da Informação.

Indo ao encontro de Floridi (2010), compreendemos que a proposição da ANT é válida, pois age como ummodo de olhar para além de entidades com vida, mas compreende entidades com existência. A análise não é biocentrista, mas ontocêntrica, ou seja, parte da essência do ser (humano ou não): "Isso sugere que há algo ainda mais elementar do que a vida, ou seja, o ser isto é, a existência e o florescimento de todas as entidades e seu ambiente global" (FLORIDI, 2010, p. 112).

Em Ética da Informação, o discurso ético diz respeito a qualquer entidade, entendida informacionalmente, isto é, não só todas as pessoas, sua cultura, bem-estar e interações sociais, e não apenas animais, plantas e sua respeitável vida natural, mas também tudo o que existe, de pinturas e livros a estrelas e pedras; qualquer coisa que pode ou vai existir, como as gerações futuras; e tudo o que era, mas não é mais, como nossos ancestrais ou civilizações antigas. [...] Este princípio da igualdade ontológica significa que qualquer forma da realidade (qualquer instância de informação/ser), simplesmente pelo fato de ser o que é, goza de mínimo, inicial, sobreposto, igual direito de existir e se desenvolver de uma maneira que é apropriada à sua natureza. (FLORIDI, 2010, p. 113).

Essa visão ontocentrista, é, como ressalta Floridi (1999), uma possibilidade de congregar elementos culturais e sociais, o que possibilita que sejamos capazes de perceber e avaliar o valor das coisas para chegar ao certo e ao errado das ações humanas, ou seja, explicálas de maneira inteligível. Só conseguiremos observar essa questão no momento em que o relatado "princípio da igualdade ontológica" for estabelecido e conseguirmos encarar isso de forma metodológica.

A ANT funciona como um tipo de proposição ético-metodológica com vistas informacionais, descartando qualquer tipo de tentativa de explicar o mundo a partir de forças que substituam atores, uma vez que um ator que pode ser substituído é um ator que carrega um viés irrelevante em sua condição de actante. Definir quem são os atores-rede é parte de um processo que pode ser considerado ontológico, pois deve investigar a essência das entidades envolvidas, aquelas que medeiam a estrutura da rede de atores.

O que a ANT propõe é, portanto, uma ruptura radical até mesmo com questões sociais, epistemológicas e ontológicas tradicionalmente colocadas à mesa. Sua base parte da negação de que os humanos têm algum tipo de privilégio apenas por serem pessoas, seres especiais. Isso deve ser utilizado como um argumento clarificador da expectativa política da Teoria, uma vez 
que não diferenciar pessoas de objetos é, como vimos, uma posição analítica, e não ética (LAW, 1992).

O relato, a descrição dos eventos e dos objetos são, desse modo, uma visão de realidade, de anotação, do vivenciado, não permitindo contemplar estruturas invisíveis que por oposição podem tornar opaca a relação entre entidades humanas e não humanas. A descrição, a partir da Teoria Ator-Rede, proporciona estudos em que as entidades são percebidas e analisadas sem que sua natureza seja critério de algum tipo de privilégio, sendo, assim, humanos e não humanos são essenciais para explicar as atividades sociais.

Uma leitura do que está "por trás" de um discurso poderia compreender apenas a explicação do mundo a partir da justificativa do social, de um contexto - seja qual for -, isto é, um estágio ainda não emancipado do pensamento. O que a ANT proporciona é, pelo contrário, a possibilidade de "um relato racional daquilo que estão falando" (LATOUR, 2012, p. 79), sem fazer com que entes opacos relatados pelos atores sejam usados como forma de escape de um relatório que não representa estritamente os fatos observados.

\section{NOTAS PARA UM PENSAR METOdOLÓgICO SOBRE A Ética DA INFORMAÇÃO A PARTIR DA TEORIA ATOR-REDE}

Pensar a ANT como uma metodologia adquire características de um raciocínio propositivamente ético, uma vez que busca congregar entidades que, em muitos casos, são preteridas, mas que, na verdade, atuam de forma decisiva na construção de redes de ações. Não há vida sem objetos e trazer a constante visão biocêntrica aos estudos (informacionais) é, como ressaltamos a partir de Law (1992), uma escolha de separação analítica, e, com certeza, não uma visão ética.

Floridi (2010, p. 109) aponta, nesse sentido, para aspectos que devem ser levados em consideração quando se estuda esses processos ético-informacionais: "Isso significa analisar informacionalmente todas as entidades envolvidas [...] e suas alterações, ações e interações, e tratá-las não como apartadas, mas como parte do ambiente informacional ao qual pertencem como próprios sistemas informacionais". Entendemos que isso se caracteriza como um pensamento ético e estabelece a relação recíproca entre a Teoria Ator-Rede e a Ética da Informação.

Indo ao encontro de Floridi (2010), compreendemos que a proposição da ANT é válida, pois age como ummodo de olhar para além de entidades com vida, mas compreende entidades

Comun. \& Inf., Goiânia, GO, v. 20, n. 1, p. 4-25, jan./jun. 2017 
com existência. A análise não é biocentrista, mas ontocêntrica, ou seja, parte da essência do ser (humano ou não): "Isso sugere que há algo ainda mais elementar do que a vida, ou seja, o ser isto é, a existência e o florescimento de todas as entidades e seu ambiente global" (FLORIDI, 2010, p. 112)

Em Ética da Informação, o discurso ético diz respeito a qualquer entidade, entendida informacionalmente, isto é, não só todas as pessoas, sua cultura, bem-estar e interações sociais, e não apenas animais, plantas e sua respeitável vida natural, mas também tudo o que existe, de pinturas e livros a estrelas e pedras; qualquer coisa que pode ou vai existir, como as gerações futuras; e tudo o que era, mas não é mais, como nossos ancestrais ou civilizações antigas. [...] Este princípio da igualdade ontológica significa que qualquer forma da realidade (qualquer instância de informação/ser), simplesmente pelo fato de ser o que é, goza de mínimo, inicial, sobreposto, igual direito de existir e se desenvolver de uma maneira que é apropriada à sua natureza. (FLORIDI, 2010, p. 113).

Essa visão ontocentrista, é, como ressalta Floridi (1999), uma possibilidade de congregar elementos culturais e sociais, o que possibilita que sejamos capazes de perceber e avaliar o valor das coisas para chegar ao certo e ao errado das ações humanas, ou seja, explicálas de maneira inteligível. Só conseguiremos observar essa questão no momento em que o relatado "princípio da igualdade ontológica" for estabelecido e conseguirmos encarar isso de forma metodológica.

A ANT funciona como um tipo de proposição ético-metodológica com vistas informacionais, descartando qualquer tipo de tentativa de explicar o mundo a partir de forças que substituam atores, uma vez que um ator que pode ser substituído é um ator que carrega um viés irrelevante em sua condição de actante. Definir quem são os atores-rede é parte de um processo que pode ser considerado ontológico, pois deve investigar a essência das entidades envolvidas, aquelas que medeiam a estrutura da rede de atores.

O que a ANT propõe é, portanto, uma ruptura radical até mesmo com questões sociais, epistemológicas e ontológicas tradicionalmente colocadas à mesa. Sua base parte da negação de que os humanos têm algum tipo de privilégio apenas por serem pessoas, seres especiais. Isso deve ser utilizado como um argumento clarificador da expectativa política da Teoria, uma vez que não diferenciar pessoas de objetos é, como vimos, uma posição analítica, e não ética (LAW, 1992).

O relato, a descrição dos eventos e dos objetos são, desse modo, uma visão de realidade, de anotação, do vivenciado, não permitindo contemplar estruturas invisíveis que por oposição 


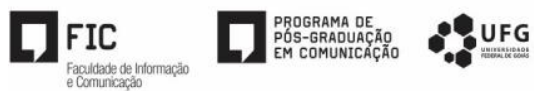

podem tornar opaca a relação entre entidades humanas e não humanas. A descrição, a partir da Teoria Ator-Rede, proporciona estudos em que as entidades são percebidas e analisadas sem que sua natureza seja critério de algum tipo de privilégio, sendo, assim, humanos e não humanos são essenciais para explicar as atividades sociais.

Uma leitura do que está "por trás" de um discurso poderia compreender apenas a explicação do mundo a partir da justificativa do social, de um contexto - seja qual for -, isto é, um estágio ainda não emancipado do pensamento. O que a ANT proporciona é, pelo contrário, a possibilidade de "um relato racional daquilo que estão falando" (LATOUR, 2012, p. 79), sem fazer com que entes opacos relatados pelos atores sejam usados como forma de escape de um relatório que não representa estritamente os fatos observados.

\section{CONSIDERAÇÕES FINAIS}

Propomos, neste trabalho, um olhar sobre a Teoria Ator-Rede a partir de uma análise ético-informacional. Essa proposição foi realizada ao compreender que no momento em que estamos em um mundo conectado por computadores, onde a comunicação de informações é cada dia mais vultosa, novos problemas ético-informacionais surgem diariamente e precisam ser estudados, apresentando respostas que, em muitos casos, não estarão descritas em estudos clássicos sobre Ética.

Nesse sentido, a Teoria Ator-Rede pode ser pensada como um instrumento de caráter metodológico para a concepção das redes a serem analisadas. Reforçamos nosso entendimento de que a ANT funciona como uma ferramenta de construção conceitual e metodológica de redes, devendo cobrir aspectos de descritividade que outras teorias e/ou métodos não cobrem, cabendo sua utilidade às demandas de pesquisas que possam surgir e que possam ser vistas como relevantes para alguns estudos.

Considerando que as tecnologias da comunicação, assim como qualquer entidade não humana, alteram as ações humanas, os eventos que emanam e que as atravessam devem ser passíveis de relato constante, descrevendo o que pode, em certo momento, ser um simples movimento e em outro se tornar uma ação destacada, já que a Ética da Informação admite prover fundamentações para tais análises. Conceber a Teoria Ator-Rede como uma escolha ética nos parece um caminho que pode ser pensado.

\section{REFERÊNCIAS}

Comun. \& Inf., Goiânia, GO, v. 20, n. 1, p. 4-25, jan./jun. 2017 
ARAUJO, E. A. A construção social da informação: dinâmicas e contextos.

DataGramaZero, v. 2, n. 5, out. 2001. Disponível em:

<http://www.dgz.org.br/out01/Art_03.htm>. Acesso em: 31 out. 2015.

BARRETO, A. A. A questão da informação. São Paulo em Perspectiva, v. 8, n. 4, p. 3-8, 1994. Disponível em: 〈http://produtos.seade.gov.br/produtos/spp/v08n04/v08n04_01.pdf>. Acesso em: 12 jan. 2016.

CAPURRO, R. A dor e a delícia da Era digital. Filosofia, Ciência \& Vida, edição 93, 2014. Disponível em: <http://www.capurro.de/moraes2014.pdf>. Acesso em: 15 jan. 2016.

Towards an ontological foundation of information ethics. Ethics and Information Technology, v. 8, n. 4, 2006, p. 175-186. Disponível em: <http://doi.org/10.1007/s10676006-9108-0>. Acesso em: 30 nov. 2016.

ELIAS, N. A sociedade dos indivíduos. Rio de Janeiro: Jorge Zahar, 1994.

FLORIDI, L. Information ethics: on the philosophical foundation of computer ethics. Ethics and Information Technology, v. 1, n. 1, p. 37-56, 1999.

The ethics of information. In: . Information: a very short introduction.

Oxford: Oxford University Press, 2010. p. 103-118.

FREIRE, L. L. Seguindo Bruno Latour: notas para uma antropologia simétrica. Comum, Rio de Janeiro, v. 11, n. 26, p. 46-65, jan./jun. 2006. Disponível em:

<http://www.ifcs.ufrj.br/ lemetro/pesquisadores/Leticia\%20de\%20Luna\%20Freire/lat our.pdf $>$. Acesso em: 14 maio 2013.

FROELICH, T. A brief history of information ethics. Bid: textos universitaris de biblioteconomia i documentació, n. 13, dez. 2004. Disponível em: <http://bid.ub.edu/13froel2.htm>. Acesso em: 31 out 2015.

HOLANDA, A.; LEMOS, A. Do paradigma ao cosmograma: sete contribuições da Teoria Ator-Rede para a pesquisa em Comunicação. In: ENCONTRO ANUAL DA ASSOCIAÇÃO NACIONAL DOS PROGRAMAS DE PÓS- GRADUAÇÃO EM COMUNICAÇÃO, 22., 2013, Salvador. Anais eletrônicos... Salvador: COMPOS, 2013. Disponível em: <http://compos.org.br/data/biblioteca_2050.pdf>. Acesso em: 10 out. 2013. 
JOHNSON, D. G. Computer ethics. In: FLORIDI, L. (Ed.). The Blackwell Guide to the Philosophy of Computing and Information. Malden, MA: BlackwellPublishing, 2004. p. $65-75$.

LATOUR, B. Ciência em ação: como seguir cientistas e engenheiros sociedade afora. São Paulo: UNESP, 2000. 438 p. 2009. $150 \mathrm{p}$

Jamais fomos modernos: ensaio de antropologia simétrica. 2. ed. São Paulo: Ed. 34,

Reagregando o social: uma introdução à Teoria Ator-Rede. Salvador; Bauru:

EDUFBA; EDUSC, 2012.

LAW, J. Notes on the Theory of the Actor-Network: Ordering, Strategy, and Heterogeneity. Systems Practice, v. 5, n. 4, p. 379-393, 1992. Disponível em: <http://doi.org/10.1007/BF01059830>. Acesso em: 2 set. 2015.

LEMOS, A. Você está aqui! Mídia locativa e teorias "materialidades da comunicação" e “ator-rede”. Comunicação \& Sociedade, ano 32, n. 54, p. 5-29, jul./dez. 2010. Disponível em: <http://dx.doi.org/10.15603/2175-7755/cs.v32n54p5-29>. Acesso em: 14 set. 2015.

MANSANO, S. R. V. Alguns desafios colocados para a pesquisa qualitativa na contemporaneidade. Revista Espaço Acadêmico, n. 136, p. 1-9, set. 2012. Disponível em: $<$ http://periodicos.uem.br/ojs/index.php/EspacoAcademico/article/view/18400>. Acesso em: 10 jan. 2016.

MOOR, J. H. What is Computer Ethics? Metaphilosophy, v. 16, n. 4, p. 266-275, 1985. Disponível em:

<http://web.cs.ucdavis.edu/ rogaway/classes/188/spring06/papers/moor.html>. Acesso em: 22 out. 2016.

MORAES, M. A ciência como rede de atores: ressonâncias filosóficas. História, Ciências, Saúde-Manguinhos, Rio de Janeiro, v. 11, n. 2, p. 321-333, 2004. Disponível em: <http://www.scielo.br/scielo.php?script=sci_arttext\&pid=S0104-59702004000200006>. Acesso em: 19 out. 2014.

MORIN, E. O paradigma complexo. In: Introdução ao pensamento complexo. 4. ed. Porto Alegre: Sulina, 2011.

NOBRE, J. C. A.; PEDRO, R. M. L. R. Reflexões sobre as possibilidades metodológicas da Teoria Ator-Rede. Cadernos UniFOA, n. 14, dez. 2010. Disponível em:

Comun. \& Inf., Goiânia, GO, v. 20, n. 1, p. 4-25, jan./jun. 2017 
<http://web.unifoa.edu.br/revistas/index.php/cadernos/article/view/1018>. Acesso em: 10 jan. 2017.

PEDRO, R. M. L. R. Redes e controvérsias: ferramentas para uma cartografia da dinâmica psicossocial. In: ESOCITE - JORNADAS LATINO- AMERICANAS DE ESTUDOS SOCIAIS DAS CIÊNCIAS E DAS TECNOLOGIAS, 7., 2008. Rio de Janeiro. Anais... 2008. v. 1.p. 1-18. 